\title{
FÜR SIE GELESEN
}

Gerhard Litscher

\section{Heart Rate Variability and Acupuncture}

Results from Transcontinental Studies

Verlag PAPST

ISBN 978-3-95853-169-7,

August 2016, ca. 250 Seiten

Dieses neue Buch gibt einen kompletten Überblick über die Beeinflussung der Herzratenvariabilität durch:

- Akupunktur mit Nadel,

- Akupunktur mit Elektrostimulation,

- Akupressur mitVibration,

- Laserakupunktur,

- i.v. Laserapplikation.

Es wurden die Daten von 233 Patienten, 42 Gesunden und 49 Tieren für die in Buchform zusammengefassten 19 Manuskripte (bereits peer-reviewed) ausgewertet. Im Wesentlichen wurden die praktischen Akupunkturund andere Reizanwendungen in China durchgeführt und die EKGs aufgezeichnet. Dann wurden die Daten über das Internet an Prof. Dr. Litscher, Medizinische Universität von Graz, geschickt und dort ausgewertet.

Dieses Vorgehen demonstriert eine wunderbare Kooperation zwischen östlicher und westlicher Medizin und spart zugleich Zeit und Geld. Die Herzratenvariabilität (HRV) dient als ein verlässlicher Indikator für den Gesundheitszustand. Auf diese Weise kann man die Wirkungen von den verschiedenen Akupunkturmöglichkeiten und anderen Reizen quantifizieren. Es können beispielsweise Syndrome wie Müdigkeit und Stress durch Akupunktur gebessert werden und dies kann durch HRV-Messungen bestätigt werden. Auch konnte gezeigt werden, dass eine Punktstimulation mit dem Laser signifikante Veränderungen in der HRV messbar werden lässt - für uns erfreulich in Bezug auf die früher manchmal gehörten skeptischen Stimmen betreffs der Wirksamkeit der Laserakupunktur.

Man möchte hoffen, dass sich aufgrund dieses Buches Akupunkturärzte die mittlerweile nicht mehr so teuren HRV-Registriergeräte und -Software zulegen, damit sie sowohl für sich als auch für ihre Patienten den positiven Akupunktureffekt „Schwarz auf Weiß“ demonstrieren können.

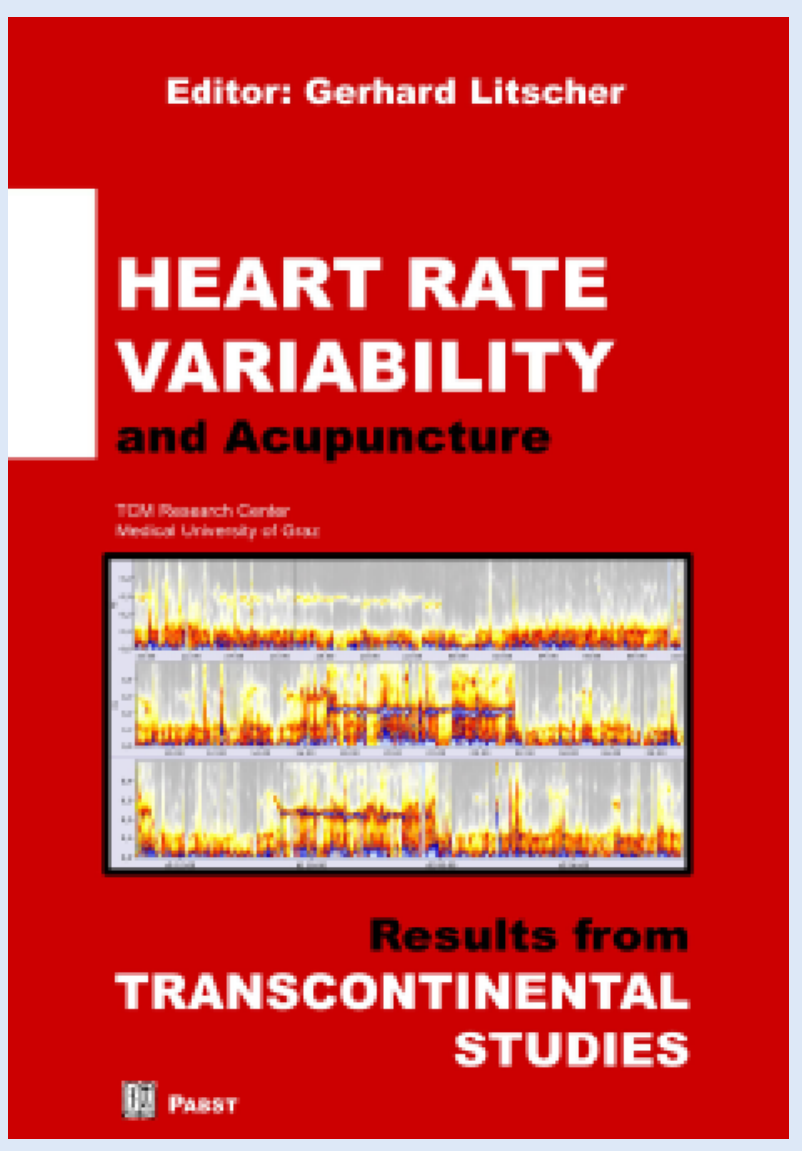

Es ist schade, dass das Buch nur in englischer Sprache erhältlich ist - am besten sollte man eine E-Mail schreiben an Herrn Prof. Dr. Litscher (E-Mail: gerhard. litscher@medunigraz.at),Verkaufspreis Euro 60, um es zugeschickt zu bekommen.

Für Sie gelesen hat

Prof. mult. h.c. China Dr. med. Frank Bahr

Präsident der EATCM

Marsopstr. 25, 81245 München

bahr@eatcm.de 